\title{
Engaging a Disadvantaged Community in Identifying Determinants of Child Neglect using Health Promotion Approach: An Experience from a Sri Lankan Study
}

\author{
N. Rathnayake ${ }^{1 *}$, S. De Silva Weliange ${ }^{2}$, G.N.D. Guruge ${ }^{1}$
}

\begin{abstract}
Child neglect is a form of child maltreatment that causes adverse short and long term consequences. Neglect is a public health problem in Sri Lanka and throughout the world. The aim of this qualitative study was to identify the determinants of neglect with a disadvantaged community in Sri Lanka using health promotion approach. Mothers having at least one child in the age range 5-18 years, and the elder child of each mother within the age range 5-18 years were included in the sample. The sample size was 42 mothers and 42 children. The period of determinant identification took an average of three months. Participatory methods in accordance with the health promotion approach were used. Discussions between principal investigator and the participants were recorded, transcribed, translated to English, and analyzed using thematic and content analysis. Without the involvement of the principal investigator, children identified four determinants as poor economy, domestic violence, alcohol abuse of parents and un-education of mothers and mothers identified five determinants. Poor resources and poor economy were the first two determinants identified by mothers. After the facilitation by the principal investigator, children identified another seven determinants, and mothers identified another thirteen determinants. Mothers and children separated determinants in to levels as individual, family, and community level. Of the total identified determinants, mothers and children collectively prioritized poor practices of mothers, poor mother-child relationships, and poor social support to be addressed. Disadvantaged community mothers and children could identify and prioritize determinants of neglect successfully with minor guidance through a health promotion approach.
\end{abstract}

Keywords: Child neglect, Determinants, Disadvantaged, Health promotion

Asian Pac. J. Health Sci., (2020); DOI: 10.21276/apjhs.2020.7.2.1

\section{INTRODUCTION}

World Health Organization (WHO) defines child neglect as the failure to provide things for the child development in aspects of child health, education, safety, nutritious meals, shelter, and opportunities for mental development. The WHO definition further includes the inability to provide appropriate supervision and protect children from hazards. ${ }^{[1]}$ Child neglect has received the least community and scientific attention compared to sexual and physical abuse of children, although negligence also causes long term negative consequences on children. ${ }^{[2]}$

Past and recent findings conclude that child neglect can cause adverse short and long term consequences on children's social, mental, emotional, and behavioral development. ${ }^{[3]}$

In cases of neglect, the deaths of children are mainly due to the absence of the caregiver at a critical situation. ${ }^{[4]}$ The prevalence of child neglect in East Asia and the Pacific region is estimated to ranges from $22-32 \%$ for both males and females. ${ }^{[5]}$ In highincome countries, one in ten children is neglected every year. ${ }^{[2]}$ In Sri Lanka, National Child Protection Authority (NCPA) receives many complaints about cases of child abuse; some are through the helpline 1929, some are written, and some are oral. In 2013, 10,273 cases of child abuse were reported, and among those 2030 complaints were on violence against children, 1263 complaints were on not having access to compulsory education, and 1101 complaints were on child neglect in accordance with Children and Young Persons Ordinance. ${ }^{[6]}$ For abuse or neglect of children, a number of risk factors working at different levels contribute, not a single factor. To deal with child abuse and neglect, the interactions between these factors should be well understood. ${ }^{[7]}$ The complex factors that cause child neglect should be understood in order to develop effective interventions. ${ }^{[8]}$ According to many studies, child maltreatment is concentrated in disadvantaged settings. ${ }^{[9]}$ The identification of determinants of child neglect is important, and
${ }^{1}$ Department of Health Promotion, Faculty of Applied Sciences, Rajarata University of Sri Lanka, Mihintale, Sri Lanka

${ }^{2}$ Department of Community Medicine, Faculty of Medicine, University of Colombo, Sri Lanka

Corresponding Author: N. Rathnayake, Department of Health Promotion, Faculty of Applied Sciences, Rajarata University of Sri Lanka, Mihintale, Sri Lanka, Email: nadeeka93rathnayake@gmail.com

How to cite this article: Rathnayake N, Weliange SD, Guruge GND. Engaging a Disadvantaged Community in Identifying Determinants of Child Neglect using Health Promotion Approach: an Experience from a Sri Lankan Study. Asian Pac. J. Health Sci., 2020; 7(2):1-6

Source of support: Nil

Conflict of interest: None

Received: 19/01/2020 Revised: 26/02/2020 Accepted: 29/03/2020

the capacity of disadvantaged people to identify determinants of neglect that prevail within their communities need to be tested. Thus, the aim of this qualitative study was to identify the determinants of child neglect with a disadvantaged community in the Anuradhapura district, Sri Lanka using a health promotion approach. Health promotion is the process that the people take over the control of the factors that affect their health, and through that, they improve health. The most specific feature of Health Promotion is 'being a process'. ${ }^{\text {[10] }}$ Disadvantaged communities are involved in identifying and addressing determinants of health issues in the health promotion approach. ${ }^{[11]}$ Health Promotion is a cost-effective approach for improving the health and wellbeing of communities. ${ }^{[12]}$ There is a lack of published data available where the disadvantaged communities or children identify the determinants of neglect. This study gives evidence that mothers and children in a disadvantaged community identify determinants of child neglect through a health promotion approach. 


\section{Materials and Methods}

\section{Study Design and Purpose}

This qualitative study was conducted to identify determinants of child neglect with a disadvantaged community in Sri Lanka. The study followed a community-centered participatory method based on a health promotion approach.

\section{Study Setting and Population}

A disadvantaged community in Anuradhapura District, Sri Lanka, was selected purposively to carry on this study with a disadvantaged setting. The study population was mothers and children in the community.

\section{Inclusion and Exclusion Criteria}

All mothers in the community who have at least one child in the age range 5-18 years were selected for the sample and mothers having children already married or children living away from home were excluded from the sample. The elder child (within the age range 5-18 years) of all mothers in the sample were also included.

\section{Sampling and Sample Size}

All mothers and their children who fulfill eligibility criteria were selected for the sample. It was 42 mothers and 42 children. Thus, the total sample size was 84 .

\section{Study Period}

The period of determinant identification with mothers and children took an average of three months.

\section{The Conceptual Framework used for Identifying Determinants of Child Neglect}

For the process of determinant identification, a conceptual framework was adopted from the community-based health promotion intervention model decided by Samarasinghe and colleagues in 2011. ${ }^{[10]}$ In a study by Guruge and colleagues in $2017^{[13]}$ also, an adopted framework from the above Samarasinghe model has been used. The adopted framework for this study (Figure 1) illustrates both subject content and process flow with the health promoter's mediation. Subject content is given as four steps in the framework.

According to the framework, the community will identify preventing child neglect as a collective goal in step 1. In step 2 , the community will understand about determinants of child neglect that operate on different levels. Determinant analysis and identification of effective actions to address those will be done by the community in step 3 . In step 4 , the necessary actions will be decided and implemented by the community.

\section{Identification of Determinants of Child Neglect with Study Participants}

A series of discussions and small group activities were conducted with study participants in accordance with the steps in the conceptual framework. The process of determinant identification was started with children, and later the participation of mothers was obtained. According to step 1, the study community needs to set a collective goal to prevent child neglect before identifying determinants. Thus, four interactive discussions were facilitated by the principal investigator with children on the topics of happiness and wellbeing, reasons for being unhappy and poor wellbeing, needs of children and child neglect, warning signs, and harm of neglect on physical, mental, and social health. These discussions were conducted in four separate days and each discussion was for a period of 45 minutes to 1-hour. The principal investigator used pictures and charts as supportive aids for discussions and to generate enthusiasm for children. As outcomes of these initial discussions, children started to mark their everyday moods (ex. happy, sad or angry) on a calendar, identified that majority of children were not happy after analyzing the calendar after a week, identified that all children in the community are not getting their needs fulfilled and child neglect is an issue in the community. At the end of the fourth discussion, children set a goal to prevent child neglect in the community. According to step 2, the process was directed towards identifying determinants because, currently, the children have a background understanding of neglect. For the ease of facilitating group discussions, five children's groups were formed considering age and gender distribution. A discussion around one hour was facilitated with children about determinants of neglect, and first, they were asked to mention any determinant without the involvement of the principal investigator. After, the principal investigator involved and moderated the discussion in a way that children could identify more superficial and less visible determinants of neglect. Then, a discussion was facilitated about levels of determinants such as individual level, family level, and community level determinants as in step 2. Children were given an opportunity for collective reflection and analysis of determinants with the guidance of the principal investigator.

After the determinant identification by children, principal investigators facilitated a discussion around 45 minutes with children on the importance of identifying determinants by mothers too. As the outcome of the discussion, ten 'story cards' (paper cards on which stories related to neglect are written using bold letters) were developed by children with the guidance of the principal investigator. These story cards were used to facilitate two interactive discussions with mothers. Each discussion was for around 45 minutes. At the first discussion, children read and explained stories to mothers, and mothers were allowed to mention any determinant of neglect, and the second discussion was moderated

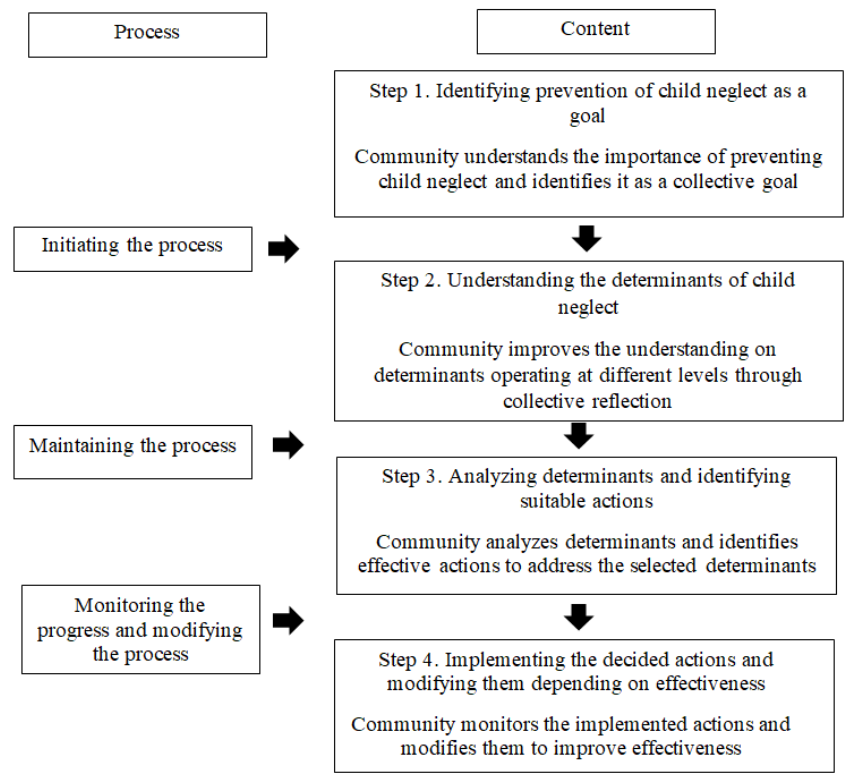

Figure 1: Conceptual framework for identifying determinants. ${ }^{[10,13]}$ 
by the principal investigator and guided mothers to identify more determinants of neglect.

After the determinant identification by mothers, a discussion was facilitated with children for about 30 minutes by the principal investigator about identifying interactions between determinants. Thus, a determinant chart was drawn by children, including all the determinants identified by them and by mothers. On that chart, the connections between determinants were identified by children with the facilitation of the principal investigator. As given in step 3 of the conceptual framework, a discussion around one hour was facilitated by the principal investigator with both mothers and children to analyze and prioritize the determinants to be addressed to prevent or reduce child neglect in the community. Principal investigator mentioned a list of determinants of child neglect present in existing literature and determinants in existing literature but not identified by mothers or children were taken into discussion. The determinant chart was explained to mothers by children with the connections between determinants. Principal investigators discussed different levels of determinants and determinants were divided again into the individual level, family level, and community level by children and mothers. Three mixed groups of children and mothers were formed and they were allowed to select the most important determinants from the determinant chart to be addressed to reduce child neglect in the community. Most important and easily changeable determinants were prioritized based on the opinion of the majority. At the end of the discussion, three determinants were prioritized by mothers and children.

\section{Data Collection and Analysis}

The discussions between the principal investigator and the study participants were tape-recorded with the consent of the participants. The collected data were transcribed, translated into English and analyzed using thematic and content analysis. Additionally, two research assistants who are the undergraduates of the health promotion degree program at the Rajarata University of Sri Lanka were trained and recruited for data collection. They were trained to observe the participants and to take notes during the sessions between the principal investigator and the study participants. When a principal investigator is taking discussions and interactive sessions with mothers and children, one observed and took notes on enthusiasm and participation, and the other took all the notes from beginning to end. Those field notes were also analyzed thematically. Further, elder children who joined with the study were trained and they measured the enthusiasm of mothers for the discussions based on the criteria, number of times that mothers asked the questions, number of times that mothers answered the questions and depending on how interestingly the mothers participated to the discussion.

\section{Ethical Considerations}

Ethical clearance was obtained from the Ethics Review Committee of Faculty of Applied Sciences, Rajarata University of Sri Lanka. Informed consent was obtained from all study participants (mothers) and from one of the parents for children under 16. Informed consent was obtained from children above 16.

\section{Results}

\section{Study Participants}

The socio-demographic data of mothers are given in Table 1. This is an ethnic minority, and their main ethnicity is 'Thelingu' $(88.1 \%$ of mothers). The main occupation of mothers is fortune-telling (64.3\%). Mothers go for fortune-telling and stay on the streets, most times with children. The majority of mothers (83.3\%) had not schooled. The monthly income of the majority of households (83.3\%) is below 5000 LKR. And, $40.5 \%$ of mothers who joined with the study were young mothers in the age range of 21-25 years.

Data about age, gender, and schooling of children are given in Table 2. Only one child in the community was regularly schooling. $52.4 \%$ of children who joined with the study were in the age range $10-18$ years, and $47.6 \%$ were in the age range $5-9$ years.

Table 1: Socio-demographic data of mothers

\begin{tabular}{|c|c|c|c|}
\hline & & $\begin{array}{l}(n=42) \\
\text { Number }\end{array}$ & $\%$ \\
\hline \multirow[t]{5}{*}{ Age } & $<20$ & 6 & 14.3 \\
\hline & $21-25$ & 17 & 40.5 \\
\hline & $26-30$ & 11 & 26.2 \\
\hline & $31-35$ & 6 & 14.3 \\
\hline & $>36$ & 2 & 4.8 \\
\hline \multirow[t]{3}{*}{ Education } & Not schooled & 35 & 83.3 \\
\hline & Grade 1-5 & 5 & 11.9 \\
\hline & Grade 6-11 & 2 & 4.8 \\
\hline \multirow[t]{5}{*}{ Occupation } & Fortune telling & 27 & 64.3 \\
\hline & Selling incense sticks & 9 & 21.4 \\
\hline & Selling books in buses & 3 & 7.1 \\
\hline & Other & 2 & 4.8 \\
\hline & No job & 1 & 2.4 \\
\hline \multirow[t]{3}{*}{ Ethnicity } & Thelingu & 37 & 88.1 \\
\hline & Sinhala & 5 & 11.9 \\
\hline & Other & 0 & 0 \\
\hline \multirow[t]{3}{*}{ Religion } & Christianity & 37 & 88.1 \\
\hline & Buddhism & 5 & 11.9 \\
\hline & Other & 0 & 0 \\
\hline \multirow{5}{*}{$\begin{array}{l}\text { Monthly income of } \\
\text { household }\end{array}$} & $<5000$ & 35 & 83.3 \\
\hline & $5000-10000$ & 6 & 14.3 \\
\hline & $10000-20000$ & 1 & 2.4 \\
\hline & $20000-30000$ & 0 & 0 \\
\hline & $>30000$ & 0 & 0 \\
\hline \multirow[t]{3}{*}{ No. of children } & $<2$ & 20 & 47.6 \\
\hline & $3-4$ & 14 & 33.3 \\
\hline & $>5$ & 8 & 19 \\
\hline \multirow[t]{6}{*}{ Marital status } & Married & 24 & 57.1 \\
\hline & Unmarried & 2 & 4.8 \\
\hline & Divorced & 1 & 2.4 \\
\hline & Widowed & 1 & 2.4 \\
\hline & Separated & 12 & 28.6 \\
\hline & Remarried & 2 & 4.8 \\
\hline
\end{tabular}

Table 2: Socio-demographic data of children

\begin{tabular}{llll}
\hline & & $\begin{array}{l}(n=42) \\
\text { Number }\end{array}$ & $\%$ \\
\hline Age & $5-9$ & 20 & 47.6 \\
\multirow{3}{*}{ Gender } & $10-18$ & 22 & 52.4 \\
& Male & 19 & 45.2 \\
\multirow{3}{*}{ Schooling } & Female & 23 & 54.8 \\
& Go school regularly & 1 & 2.4 \\
& Go school irregularly & 7 & 16.7 \\
& Not schooling & 34 & 81 \\
\hline
\end{tabular}




\section{Identified and Prioritized Determinants}

The determinants identified by children without the involvement of principal investigators in the facilitation process are listed in Table 3. Children identified the poor economy as the most influential factor for neglect. They recognized that children in households where domestic violence presents are more prone to neglect. According to children, alcohol abuse of the parents makes them neglected, and un-education (school education) of mothers is also a determinant for child neglect.

The determinants of child neglect identified by children after the facilitation by the principal investigator are listed in Table 4. Poor practices of parents that are inherited from the culture was identified as an important determinant of child neglect by children. Children identified, poor parent-child relationships and poor communication between parents and children cause child neglect. In the mid of the discussion, children recognized having no dreams about the future of children as further an essential determinant of neglect. According to children, parents pay no attention to needs of children like education or health when they don't have dreams or expectations for their children. Poor social support for mothers for child caring was identified as a deeper level determinant for child neglect. Towards the end of the discussion, children identified poor parenting skills and parental stress also as determinants of neglect with the facilitation of the principal investigator.

Five determinants of neglect identified by mothers without the facilitation of the principal investigator are listed in Table 5. Poor resources and poor economy were the first determinants mentioned by mothers. According to the opinion of mothers, children tend to neglect more due to the above mentioned two determinants. Doing jobs by mothers was identified as an important determinant of neglect. Mothers mentioned that doing jobs by mothers reduces the time to be with children and care for children. Mothers identified a higher number of children as a prominent determinant for neglect. Stigma by the outer society was identified as a deeper level determinant for child neglect.

The determinants of neglect identified by mothers with the facilitation of the principal investigator are listed in Table 6.

Table 3: Determinants of child neglect identified by children without the involvement of principal investigators in the facilitation process
1. Poor economy
3. Alcohol abuse of parents
2. Domestic violence
4. Un-education of mothers

Table 4: Determinants of child neglect identified by children after the facilitation of the principal investigator

1. Poor practices of parents

2. Poor relationships and poor communication between parents and children

3. Children and parents don't have dreams about future

4. Characteristics of children such as stubbornness

5. Poor social support

6. Poor parenting skills

7. Parental stress

Table 5: Determinants of child neglect identified by mothers without the involvement of the principal investigator in the facilitation process

\begin{tabular}{ll}
\hline 1. Poor resources & 4. A higher number of children \\
2. Poor economy & 5. Stigma by outer society \\
3. Mothers are going for jobs &
\end{tabular}

Mothers identified alcohol abuse of parents and the presence of domestic violence tends to cause child neglect with the facilitation of the principal investigator. Characteristics of mothers such as teen mothers, single mothers, un-education of mothers, and characteristics of children such as disabled children, stubborn and aggressive children were identified as determinants of neglect at the mid of the discussion. The aggressiveness of parents towards children was also identified as a determinant of child neglect. Mothers also identified, having no dreams about the future of children, poor social support, poor practices of parents inherited by culture based on cultural beliefs and poor parent-childd relationships as important determinants of neglect as children did. Migration to other places during festive seasons and not having permanent residences was identified as a communityspecific determinant of neglect by mothers. In the later part of the discussion, mothers identified negative attitudes on gender roles like 'looking into needs of children and fulfilling them is a responsibility of a mother' as a less visible determinant that causes mothers more stress leading to unintentional child neglect.

After explaining the determinant chart to the mothers by children, mothers, and children together divided the identified determinants into levels as individual level, family level, and community level. The determinants divided into levels are listed in Table 7.

Mothers and children prioritized three important determinants to be addressed and changed in the community. Those three determinants are listed in Table 8.

\section{Discussion}

According to many studies, child maltreatment is concentrated in disadvantaged settings. A number of socio-economic features of neighborhoods are shown to correlate with rates of child maltreatment. ${ }^{[14]}$ Thus, the selection of a disadvantaged community for the present study to identify determinants of neglect is itself a strength. The socio-demographic data of the study participants, especially data about education, occupation, and monthly income, prove this is a disadvantaged community. The main reason behind the success of the study is the use of community-based participatory methods throughout the study. The other thing is, children and mothers were not asked to identify determinants at once. A conceptual framework was

Table 6: Determinants of child neglect identified by mothers after the facilitation of the principal investigator

1. Alcohol abuse of the parents

2. Domestic violence

3. Having no dreams about the future of children

4. Mothers are less enthusiastic about caring about children

5. Characteristics of children such as, disabled, stubborn and aggressive

6. Characteristics of mothers such as single mothers and teen mothers

7. Un-education of mothers

8. Aggressiveness of parents towards children

9. Poor social support

10. Culturally inherited practices of parents

11. Poor parent-child relationship

12. Migration to other places

13. Negative attitudes on gender roles 
Table 7: Determinants divided into levels

\begin{tabular}{lll}
\hline Individual-level determinants & \\
\hline - Characteristics of children such as, disabled, stubborn and aggressive & $\cdot$ Poor practices of parents \\
- Characteristics of mothers like teen mothers and single mothers & $\cdot$ Mothers are going for jobs \\
- Un-education of mothers & Mothers are less enthusiastic about caring about children \\
- A higher number of children & Plcohol abuse of parents & Poor parenting skills \\
- Parental stress & Having no dreams about children' future \\
\hline Family level determinants & Aggressiveness of parents towards children \\
\hline Domestic violence & Poor parent-child communication and relationships \\
\hline$\quad$ Migration to other places & Poor household economy \\
\hline Community-level determinants & \\
\hline Poor resources & Poor social support \\
\hline
\end{tabular}

Table 8: Prioritized determinants

\begin{tabular}{l} 
- $\quad$ Poor practices of mothers (culturally inherited practices) \\
- $\quad$ Poor mother-child relationships \\
\hline
\end{tabular}

followed and there was a proper engagement with the group to identify child neglect as an issue in the community. The main finding of the study is disadvantaged mothers and children could identify the determinants of child neglect. Children who are the victims of neglect readily understood the need of identifying determinants of neglect before addressing the issue. When the principal investigator mentioned about determinants in existing literature, mothers and children understood them as applicable to their setting.There is a lack of published literature available, where disadvantaged communities and children have involved in identifying determinants of child neglect. Study participants in the present study could identify the determinants already mentioned in existing literature. In a review of qualitative studies by Morantz and colleagues in 2013 about maltreatment among orphaned children in extended families in Sub-Saharan Africa has found poverty, living with a non-biological caregiver, stigma and alcohol abuse as risk factors for child maltreatment. ${ }^{[14]}$ Exposure to child maltreatment is not randomly distributed in populations. Children in low-income families, ${ }^{[15]}$ children with unemployed parents, ${ }^{[16]}$ and low educated parents ${ }^{[15]}$ or single parents $s^{[17]}$ are at a higher risk to exposure to child abuse or neglect with compared to their counterparts. Lack of financial resources has been identified as a predictor of neglect in many studies. ${ }^{[18,19]}$ The study participants in the present study could identify the above determinants. Poor economy was identified by both mothers and children in the present study as a determinant for child neglect. Stigma by outer society was also identified by mothers in the present study as a determinant for neglect without any facilitation. Children in the present study could identify un-education of mothers as a determinant for neglect and mothers mentioned characteristics of mothers like, being single also as determinants for neglect. The determinants of alcohol and drug abuse, domestic violence, lack of parenting skills and stress and lack of support have been identified by Kudagammana, 2010 as risk factors for child abuse and neglect. ${ }^{[20]}$ Children and mothers in the present study could identify these determinants as well. Domestic violence and parental alcohol abuse were quickly identified by children without any facilitation. Poor parenting skills, parental stress and poor social support were identified by children after the facilitation of the principal investigator. Domestic violence, alcohol abuse and poor community support were identified as determinants of neglect by mothers after the facilitation by the principal investigator. A major strength of the study was the involvement of the children who are the victims of neglect and mothers who are the perpetrators. When preventing violence against children, children need to be provided not only the benefits. They need to be engaged as agents of change in the process. ${ }^{[21,22]}$ Children in the present study were able to identify the determinants, as well as they assisted in guiding the mothers to identify the determinants. The principal investigator gave inputs and facilitated the process. Discussions with public groups and communications with children and parents are to be facilitated when working on issues related to child maltreatment. ${ }^{[21,23]}$ Always participatory activities between mothers and children were carried out throughout the study. As examples, children explained 'story cards' to the mothers, and children explained determinant chart to the mothers, levels of determinants were identified by both mothers and children together. A weakness of the study was, measurements by children and research assistants were subjective. Children identified and gave marks on the enthusiasm of mothers for the discussions. Levels of understanding of children are different, leading to subjectivity in the measurements. Possible precautions were taken to avoid subjectivity such as, criteria were defined to measure enthusiasm and these criteria were well discussed and explained to children. Children were trained by the principal investigator to assess the enthusiasm of mothers with examples. Research assistants also were trained by the principal investigator to measure the enthusiasm of participants. These measurements are not the weaknesses because it improved the enthusiasm of both children and mothers to the process. But in replications, the same method will not able to be applied, and measures are to be developed in partnership with the study community.

\section{Conclusions}

The children who are the victims of neglect were quick in identifying determinants of neglect with relatively small facilitation. Mothers with no or little formal education and with no training on approach or research may easily identify the underlining determinants of child neglect with the facilitation of the principal investigator and children. Disadvantaged community, mothers and children were capable of identifying and categorizing determinants into levels such as individual, family, and community-level determinants. Participatory methods based on the health promotion approach are effective in guiding disadvantaged communities to identify 
determinants of child neglect. The findings from the study can be used to modify ongoing interventions to prevent child neglect. The ongoing actions to address neglect are based on already identified determinants, and there is no active engagement of victims and perpetrators of neglect to identify the determinants. The officers, child health activists, and other field staff who work on matters of child neglect and other forms of child maltreatment can be trained on participatory methods and health promotion approaches. This approach can be used with disadvantaged communities where there is a higher chance for neglect to occur. General and targeted effective interventions can be developed after the identification of real causes of neglect with disadvantaged communities.

\section{AcKnowledgment}

Authors would like to thank Prof. Nalika Gunawardena for providing writing assistance for the research proposal. Also, authors are grateful to the research assistants and study participants in the community.

\section{References}

1. World Health Organization. Report of the consultation on child abuse prevention, 29-31 March 1999, WHO, Geneva. World Health Organization; 1999.

2. Gilbert R, Widom CS, Browne K, Fergusson D, Webb E, Janson S. Burden and consequences of child maltreatment in high-income countries. The lancet. 2009 Jan 3;373(9657):68-81.

3. Hildyard KL, Wolfe DA. Child neglect: developmental issues and outcomes. Child abuse \& neglect. 2002 Jun 1;26(6-7):679-95.

4. Margolin, L. Fatal Child Neglect. Journal of Child welfare, 1990; 69, 309-319.

5. UNICEF EAPRO. (2014). Violence against Children in East Asia and the Pacific: A Regional Review and Synthesis of Findings, Strengthening Child Protection Series, No. 4. Bangkok.

6. National child protection authority Sri Lanka. (2013). Annual Report. Colombo, Sri Lanka Available at: https://www.parliament.lk/uploads/ documents/paperspresented/annual-report-national-child-protection authority-2013.pdf. (03 Jan. 2020).

7. UNICEF. (2013). Preventing and Responding to Violence, Abuse, and Neglect in Early Childhood: A Technical Background Document, Child Protection Section. New York.

8. Hlady,J. Child neglect: Evaluation and management. BC Med J, 2004; $46(2), 77-81$.

9. Coulton, C.J., Crampton, D.S., Irwin, M., Spilsbury, J.C. and Korbin, J.E. Erratum to "How neighborhoods influence child maltreatment: A review of the literature and alternative pathways". Child Abuse and Neglect, 2009; 33(6): 402.
10. Samarasinghe, D., Fernando, M., Guruge, D., Amunugama, S., Indrawansa, S. and Ranasinghe, R. Health Promotion Process. 2011; Colombo: Health Education Bureau, Ministry of Health, Sri Lanka.

11. Peris K, Guruge D, Perera M, Senarathne L. Children's Health Country Programme: First Phase Programme Review 2010-2012. HaPAN/PLAN/ Rajarata University of Sri Lanka. 2013.

12. World Health Organization. (2009). Milestones in health promotion; statements from Global Conferences. World Health Organization; 2009. Available at: http://www.who.int/ health promotion/Milestones_ Health_Promotion_05022010.pdf.(30 Dec.2019)

13. Guruge, N.D.G., Goonasekara, M., Dharmaratne, S.D. and Gunathunga, M.W. Engaging a rural community in identifying determinants of low birth weight and deciding on measures to improve low birth weight: an experience from a Sri Lankan study. Journal of Health, Population and Nutrition, 2017; 36:41.

14. Morantz, G., Cole, D., Vreeman, R., Ayaya, S., Ayuku, D. and Braitstein, P. Child abuse and neglect among orphaned children and youth living in extended families in sub-Saharan Africa: What have we learned from qualitative inquiry? Vulnerable Children and Youth Studies, 2013; 8(4):338-352

15. Cancian, M., Yang, M.Y. and Slack, K.S. The Effect of Additional Child Support Income on the Risk of Child Maltreatment. Social Service Review, 2013; 87, 3: 417-437.

16. Bill, G., Gary, T., Bill, C., Isobel, F., Martin, R. and Allan, L. Unemployment rates, single parent density, and indices of child poverty: their relationship to different categories of child abuse and neglect. Child Abuse and Neglect, 1998; 22:79-90.

17. Mersky, J.P., Berger, L.M., Reynolds, A.J. andGromoske, A.N. Risk factors for child and adolescent maltreatment: A longitudinal investigation of a cohort of inner-city youth. Journal of Child Maltreatment, 2009; $14,73-88$.

18. Hornor, G. Child Neglect: Assessment and Intervention. Journal of Pediatric Health Care, 2013; 28 (2): 186- 192.

19. Slack, K., Berger, L., DuMont, K., Yang, M., Kin, B., Ehrhard-Dietzel, S andHoll, J. Risk and protective factors for child neglect during early childhood: A cross-study comparison. Children and Youth Services Review, 2011; 33:1354-1363.

20. Kudagammana, S.T. Defining and comprehending child abuse at present times. Sri Lanka journal of forensic medicine, science and law, 2010; 1(2):12

21. UNICEF. (2017). Preventing violence against children in Sri Lanka, Country Discussion Paper.

22. United Nations General Assembly. (2007). Report of the independent expert for the United Nations study on violence against children. Sixtysecond session. Available at: https://documents-dds-ny. un.org/doc/ UNDOC/GEN/N07/ 452/43/PDF/ N0745243. (10 Jan. 2020)

23. World Health Organization. (2006). International Society for Preventing Child Abuse and Neglect. Preventing Child Maltreatment: a guide to taking action and generating evidence. Geneva, Switzerland, WHO 